\title{
A educação entre obstáculos epistemológicos e vícios intelectuais ${ }^{1}$
}

David Velanes ${ }^{2}$

Elyana Barbosa ${ }^{3}$

Na história do pensamento, tem sido bastante relatado os problemas acerca dos entraves que dificultam o acesso à verdade. A alegoria da caverna de Platão, a teoria dos ídolos de Bacon, as meditações de Descartes, entre outros, são grandes exemplos de reflexões filosóficas relacionadas com o problema da busca do conhecimento. Entretanto, nenhum desses autores resolveu absolutamente tal questão deixando suas contribuições para o pensamento contemporâneo. Este, por sua vez, ora oferece respostas diferentes daqueles autores, ora aprofundam suas reflexões.

Nas ideias contemporâneas, o problema do acesso ao conhecimento verdadeiro já não se restringe ao saber científico. Vários estudos têm se ocupado de como esse problema se manifesta também no indivíduo da vida cotidiana, uma vez que este se encontra diante de diversas dificuldades na busca do saber em uma época na qual já se fala de "pós-verdade". Isso quer dizer que atualmente não podemos trabalhar com a distinção clássica entre sujeito da ciência e o sujeito da vida comum quando a questão é a construção do saber.

Ora, ambos não se tratam de um mesmo ser humano que possui uma vida intelectual? Um mesmo ser humano não transita entre as diversas esferas do conhecimento, a saber, à científica, a filosófica, a artística, a religiosa e o senso comum?

É verdade que o sujeito que faz ciência trabalha com um método com o qual ele pode chegar de maneira mais segura a um conhecimento objetivo. É verdade também que o homem da ação, da vida comum, ao não pensar com base em um método preciso tende, de maneira

\footnotetext{
${ }^{1}$ Este trabalho é o resultado de várias reflexões que se originaram a partir do Congresso Bachelard no Brasil: a filosofia bachelardiana e os impactos da sociedade (online) - 2020, que contou com a presença de diversos pesquisadores do pensamento bachelardiano. Link:

https://www.youtube.com/watch?v=UR8DLW6hzNk\&t=4s\&pbjreload=101. 0 texto contou, para sua produção, com os recursos de financiamento da minha pesquisa de Doutorado, Bolsa CAPES.

${ }^{2}$ Doutorando em Filosofia pela Universidade Federal da Bahia - UFBA, Salvador. Bolsista CAPES. dvelanes@gmail.com

${ }^{3}$ Professora da Pós-graduação em Filosofia, Universidade Federal da Bahia - UFBA, Salvador. elyb@uol.com.br
} 
geral, a se deparar com maiores equívocos intelectuais em relação aos primeiros. Em todo caso, mesmo em tal distinção clássica, é preciso considerar a vida intelectual do ser humano é permeada por elementos psicólogos pelos quais o próprio método científico pode falhar na busca da verdade. É com base nessa visão integral acerca da vida intelectual do sujeito que apresentamos as ideias deste trabalho. Para tanto, recorremos às ideias de Gaston Bachelard e de Quassim Cassam.

A nossa proposta é compreender como os conceitos utilizados pelos dois autores emergem no contexto da Educação, a saber, as noções de obstáculos epistemológicos e vícios intelectuais dos dois filósofos, respectivamente. É nesse domínio que buscaremos refletir a respeito da união entre os dois conceitos. Lançamos mão, em vista de tal objetivo, além das ideias dos dois filósofos, a análise de Velanes (2020) para quem essas duas noções são complementares, na medida em que ambas se referem a aspectos psicológicos do sujeito epistêmico. Desse modo, acreditamos que este trabalho evidencia de que forma ambos os conceitos contribuem no entendimento do problema da construção do conhecimento no processo de ensino-aprendizagem.

A noção de obstáculos epistemológicos bachelardiana se refere aos entraves que impedem o progresso do saber. Segundo Bachelard (1977), esse conceito não se trata nem de empecilhos externos, como a complexidade e fugacidade dos fenômenos, nem da vulnerabilidade dos sentidos humanos. Ele se refere aos entraves que aparecem no ato do conhecimento e cuja raiz se encontra nas formas de pensar do sujeito. Isso significa que os obstáculos ao saber são de ordem espiritual, ou seja, fazem parte da atividade psíquica e investigativa do agente conhecedor. ${ }^{4}$

É no ato mesmo de conhecer, intimamente, que aparecem, por uma espécie de imperativo funcional, lentidões e conflitos. É aí que mostraremos causas de estagnação e mesmo de regressão, detectaremos causas de inércia às quais daremos o nome de obstáculos epistemológicos (BACHELARD, 1977, p.13).

\footnotetext{
${ }^{4}$ É na sua obra La formation de l'esprit scientifique (1938) que Bachelard identifica e analisa os obstáculos que se apresentaram na constituição da ciência moderna. Quais sejam: a experiência primeira, o conhecimento geral, o obstáculo verbal, o substancialismo, o conhecimento unitário e pragmático, o obstáculo animista e o obstáculo ao conhecimento quantitativo. $\mathrm{O}$ autor destaca que, se de um lado a ciência moderna se formou face à superação desses entraves, por outro, eles podem sempre retornar ao espírito científico uma vez que fazem parte da história das ideias.
}

Periódico Horizontes - USF - Itatiba, SP - Brasil - e021047 
Em La formation de l'esprit scientifique, Bachelard procura relacionar a noção de obstáculos a hábitos intelectuais que são adquiridos pelo sujeito do conhecimento. Esses hábitos são constituídos por ideias elaboradas em diversas épocas que se sedimentam no pensamento científico em seu decurso histórico. O problema é que esse conhecimento "[...] adquirido pelo esforço científico pode declinar. A pergunta abstrata e franca se desgasta: a resposta concreta fica. Então, a atividade espiritual se inverte e se bloqueia" (BACHELARD, 1977, p.14).

Bachelard (1977, p.15), ainda acrescenta que "um obstáculo epistemológico se incrusta no conhecimento não questionado. Hábitos intelectuais que foram úteis e sadios podem, com o tempo, entravar a pesquisa." E, ao citar Bergson, ele afirma que: "Nosso espírito [...] tem a tendência irresistível de considerar como mais clara a ideia que costuma utilizar com frequência".

Assim, Bachelard $(1999,1986)$ chama a atenção para a necessidade de aguçar o pensamento discursivo a fim de que as noções utilizadas de maneira habitual possam ser pensadas de maneira discursiva. A atividade de por os conceitos num processo discursivo pela comunidade científica deve ser a base para a atualização de ideias em face de uma realidade que se encontra em constante transformação.

É importante ressaltar que para melhor compreender a noção de obstáculo é preciso pensá-la no seio da epistemologia bachelardiana. Ou seja, Bachelard apresenta uma epistemologia trans-histórica (BONTEMS, 2010) na qual a história das ideias científicas se torna um objeto de análise e julgamento a partir do ponto de vista epistemológico. Assim, ele demonstra como determinados conceitos do passado se tornam insuficientes no movimento do saber. É nesse sentido que sua noção de recorrência histórica é importante, na medida em que ela esclarece a importância de julgar as noções do passado à luz dos conhecimentos atuais a fim de evidenciar suas limitações e, por consequência, evitar e/ou superar os obstáculos ao saber (BACHELARD, 1972, 1965).

Na análise recorrente é preciso considerar "[...] uma história que parte das certezas do presente e descobre, no passado, as formações progressivas da verdade. Assim, o pensamento científico se garante no relato de seus progressos" (BACHELARD, 1965. p.26). Então, a filosofia bachelardiana apresenta a relevância de observar a atualidade dos conceitos para que a realidade atual não seja pensada com base em noções esclerosadas, evitando-se, assim, perturbações no conhecimento. Existem ideias na realidade atual cuja persistência “[...] é 
resultante da aceitação cega de uma tradição profundamente enraizada e cuja origens são hoje completamente desconhecidas" (BACHELARD, 1977, p.43). E o filósofo francês, ainda em La Formation explica que:

Com o uso, as ideias se valorizam indevidamente. Um valor em si opõe-se à circulação dos valores. É fator de inércia para o espírito. Às vezes, uma ideia dominante polariza todo o espírito. Um epistemólogo irreverente dizia, há vinte anos, que os grandes homens são úteis à ciência na primeira metade de sua vida e nocivos na outra metade. $O$ instinto formativo é tão persistente em alguns pensadores, que essa pilhéria não deve surpreender. Mas, o instinto formativo acaba por ceder a vez ao instinto conservativo. Chega o momento em que o espírito prefere o que confirma seu saber àquilo que o contradiz, em que gosta mais de respostas do que de perguntas. $O$ instinto conservativo passa então a dominar, e cessa o crescimento espiritual (BACHELARD, 1977, p.15).

Portanto, Bachelard (1977) considera nocivo, no campo das ideias, manter-se diante de um conservadorismo intelectual. É preciso lutar contra nosso instinto conservativo em relação aos métodos de pesquisas, teorias e conceitos que são assimilados pelo sujeito. Esse combate é importante porque as revoluções que ocorrem no saber não são suficientes para aniquilar as ideias que se tornam esclerosadas. Logo, o saber científico, em seu percurso histórico, acumula uma pluralidade de noções e métodos que podem ser utilizados tacitamente como ideias claras em um novo domínio onde não encontram coerência de aplicação.

É preciso assinalar que a noção bachelardiana de obstáculo epistemológico é complexa e que, portanto, possibilita diversas interpretações (VELANES, 2020, 2018; BULCÃO, 2009; BARBOSA, 1996; LECOURT, 1978; VADÉE, 1975). No entanto, é possível notar que um elemento comum atravessa tais análises, a saber, de que tal categoria bachelardiana comporta uma origem social e uma psicológica. Convém notar que esses dois domínios são característicos da integralidade mesma do ser humano. Com efeito, Bachelard (1977) não deixa de reconhecê-los como próprio da condição humana ao afirmar que:

[...] é o homem inteiro, com sua pesada carga de ancestralidade e de inconsciência, com toda a sua juventude confusa e contingente, que teria de ser levado em conta se quiséssemos medir os obstáculos que se opõem ao conhecimento objetivo, ao conhecimento tranquilo (p.209). 
É exatamente no que concerne à caracterização acerca desses dois campos - o social e o psicológico - da noção bachelardiana de obstáculo epistemológico que Velanes (2020) identifica a relação com a noção de vícios intelectuais de Cassam (2016). Mais precisamente, o autor procura demonstrar que o ponto de contato entre os conceitos dos dois filósofos - apesar de pertencerem a problemáticas distintas - é a origem psicológica que se apresenta notoriamente como causas de perturbação no conhecimento. Segundo Velanes (2020),

[...] a noção de vícios intelectuais encontra sua correspondência com o conceito de obstáculo epistemológico na origem psicológica dessa noção bachelardiana, visto que ambas se referem àquilo que é próprio das condições psíquicas do ser humano em geral, de sua vida intelectual, como hábitos ou estilos subjetivos de pensar, e por isso, julgamos que podem se manifestar como entraves a investigações eficazes e responsáveis nos sujeitos epistêmicos em suas atividades científicas. Em outras palavras, o dogmatismo, a negligência, o orgulho intelectual, o preciosismo, etc., correspondem a uma das origens da noção de obstáculo epistemológico, na medida em que se encontram ligados às condições psicológicas do agente epistêmico e que, pela natureza mesma dessas condições, atrapalham a busca da objetividade do conhecimento científico (p. 141).

Os vícios intelectuais são, segundo Cassam (2018, 2016), estilos de pensar ligados ao caráter pessoal do sujeito epistêmico que podem comprometer investigações eficazes e responsáveis. Dessa forma, os vícios não apenas sustentam as bases de explicações oferecidas por um determinado sujeito conhecedor, mas também revela como ele se coloca diante da busca do conhecimento. Em outras palavras, os vícios intelectuais podem ser considerados como hábitos do sujeito epistêmico que fornecem modos explicativos intuitivos na abordagem de novos problemas.

Cassam (2016, p.165) considera como exemplos de vícios intelectuais (ou epistêmicos) o dogmatismo, a mente fechada e a credulidade ingênua, entre outros. Para ele, ser crédulo ingênuo é um vício, e não uma virtude epistêmica, na medida em que podemos "[...] ser facilmente enganados", e isso nos "[...] torna menos eficazes em descobrir as respostas para nossas questões", ou menos "eficazes na busca de entender os eventos" 5 .

\footnotetext{
5 "Being gullible is a vice rather than a virtue because being easily cheated or duped makes us less effective at discovering the answers to our questions and trying to understand the events we are trying to understand".
}

Periódico Horizontes - USF - Itatiba, SP - Brasil - e021047 
Outro vício apresentado pelo filósofo americano é a disposição de um indivíduo para ignorar argumentos e evidências que são contrários às suas crenças. Ele assevera que "ignorar evidências contrárias, que não são em si um traço de caráter, é exatamente o tipo de coisa esperada por alguém dogmático ou de mente fechada" 6 (CASSAM, 2016, p.165).

Para Battaly (2018), outra autora que elabora suas pesquisas no domínio da "epistemologia dos vícios"7, uma pessoa de mente fechada pode ser considerada viciosa epistemicamente quando ela não se coloca em disposição (de forma deliberada) em contextos nos quais suas concepções são ou podem ser confrontadas. Segundo a autora, essa não disposição não apenas demonstra certa falta de interesse ou uma incapacidade para o envolvimento em discussões sérias onde existem visões intelectuais importantes, mas também revela uma rejeição voluntária de ideias relevantes, diferentes ou opostas, às suas próprias convicções.

Em suma, a mente fechada, considerada como uma espécie de vício intelectual, seja para Cassam (2016), seja para Battaly (2018), diz respeito à atitude com a qual o agente epistêmico se apresenta diante de uma investigação que busca o conhecimento verdadeiro, um saber objetivo. Neste ponto, podemos acrescentar uma citação de Bachelard (1977, p.15) que reforça a análise comparativa de Velanes (2020), quando o filósofo francês diz que "[...] uma cabeça bem feita é infelizmente uma cabeça fechada". Ora, uma cabeça fechada é justamente aquela que não se permite pensar diferente dos modos habituais. O que implica, portanto, em performances epistêmicas perigosas quando se busca a verdade.

Um ponto interessante destacado por Cassam (2016) é que os vícios intelectuais nunca se apresentam de modo individual em um sujeito. Ao contrário, eles se encontram agrupados e relacionados entre si contribuindo na formação de explicações fundamentadas em evidências ou fontes não confiáveis. $\mathrm{O}$ autor identifica que a condição basilar que possibilita o agrupamento de diversos vícios é a ignorância. Assim, esclarece Velanes (2020, p. 137), que "estilos viciosos de pensar como o dogmatismo ou "mente fechada", o cinismo e a credulidade (ingênua), podem

\footnotetext{
6 "[...] ignoring contrary evidence, which is not itself a character trait, is exactly the sort of thing one would expect someone who is dogmatic or closed-minded to do".

7 "[...] um ramo da epistemologia que se concentra na natureza, identidade e significado epistemológico dos vícios intelectuais" (CASSAM, 2016, p.159-160). "[...] a branch of epistemology which concentrates on the nature, identity, and epistemological significance of intellectual vices".
} 
geralmente se encontrar interligados na mente de um mesmo indivíduo", assim como ocorre com os obstáculos epistemológicos destacados por Bachelard em sua obra de 1938.

Em Vice epistemology (2016), Cassam ainda destaca outros exemplos de vícios intelectuais, a saber: o orgulho intelectual, a negligência, o preciosismo, a insensibilidade aos detalhes, a falta de rigor, a obtusidade etc. Todos eles como formas de pensar que podem orientar a conduta de um sujeito epistêmico em uma determinada investigação, comprometendo-a.

Então, com base nas considerações supracitadas podemos dizer que as ligações entre obstáculos epistemológicos e vícios intelectuais se encontram na vida intelectual de um determinado sujeito e, como esses dois conceitos visam elucidar os problemas relativos na construção do conhecimento, podemos agora indagar como eles aparecem no contexto educativo.

Com efeito, existem diversos estudos acerca da categoria bachelardiana de obstáculo no domínio da Educação, notadamente no ensino de Química (SILVEIRA et al, 2019; PENAA; MESQUITA, 2018; LÔBO, 2007, 2002; LOPES, 1993a, 1993b; PARENTE, 1990). Diferentemente dessas investigações, nosso propósito é o de pensá-la junto à noção de vícios no contexto educativo. Ora, se é verdade que vícios e obstáculos se correspondem, então é possível encontrar tal correspondência no contexto da prática educativa. É essa empreitada que pretendemos demonstrar a partir deste ponto.

De fato, Bachelard (1977) assevera a importância do contexto escolar na propagação dos obstáculos ao saber. Ele afirma que "a noção de obstáculo epistemológico pode ser estudada no desenvolvimento histórico do pensamento científico e na prática da educação. Nos dois casos, esse estudo não é cômodo" (BACHELARD, 1977, p.17). É com base nessa consideração que o filósofo francês desfere críticas à postura metodológica rigidamente adotada por professores.

Segundo ele, os educadores ao assumir uma metodologia que não se retifica perante a uma razão e a um real mutável, não favorece aos alunos a aquisição de conhecimentos férteis. Os professores "emitem mais juízos do que ensinam! Nada fazem para curar a ansiedade que se apodera de qualquer mente diante da necessidade de corrigir sua maneira de pensar e da necessidade de sair de si para encontrar a verdade objetiva" (BACHELARD, 1977, p.209). E o autor ainda acrescenta, a propósito da metodologia em sala de aula, que "os professores, sobretudo 
na multiplicidade incoerente do ensino secundário, apresentam conhecimentos efêmeros e desordenados, marcados pelo signo nefasto da autoridade" (BACHELARD, 1977, p.244 - grifo nosso).

Ora, um ensino marcado pela autoridade parece encontrar fundamento no orgulho intelectual, que é considerado com um vício epistêmico por Cassam (2016), como já destacamos. Um educador "epistemicamente orgulhoso" de suas próprias convicções não será capaz, em tese, de se submeter a uma atividade dialógica e discursiva com seus alunos na qual suas ideias mais profundamente valorizadas poderão ser contestadas. Isso significa que seu caráter psicológico influencia sua postura autoritária na sala de aula.

Vale acrescentar que no cenário educacional brasileiro tal situação não nos parece novidade quando o assunto é a educação autoritária. Aqui, é possível lançar mão das reflexões de Freire (1987), para quem, num domínio de uma "concepção bancária da educação", o professor se considera "dono" do saber. O autor explica que:

Na visão "bancária" da educação, o 'saber' é uma doação dos que se julgam sábios aos que julgam nada saber. Doação que se funda numa das manifestações instrumentais da ideologia da opressão - a absolutização da ignorância, que constitui o que chamamos de alienação da ignorância, segundo a qual esta se encontra sempre no outro. O Educador, que aliena a ignorância, se mantém em posições fixas, invariáveis. Será sempre o que sabe, enquanto os educandos serão sempre os que não sabem. A rigidez destas posições nega a educação e o conhecimento como processos de busca... O educador identifica sua autoridade do saber com sua autoridade funcional, que opõe antagonicamente à liberdade dos educandos; estes devem adaptar-se às determinações daquele (p.33-34 - grifos nossos).

Segundo Freire (1987), a dialogicidade deve ser considerada como elemento fundamental da educação que liberta o indivíduo da ignorância. Para Bachelard (1977), o ensino precisa ser socialmente ativo, isto é, que ocorra na relação professor-aluno uma recíproca discursiva a fim de superar as ideias do senso comum e os saberes sedimentados historicamente, que são, na maioria das vezes, as bases para o pensamento dogmático que entravam o progresso do saber. Bachelard (1977) diz que:

[...] É um alto desprezo pela instrução o ato de instaurar, sem recíproca, a inflexível relação professor-aluno. A nosso ver, o princípio pedagógico 
fundamental da atitude objetiva é: quem é ensinado deve ensinar. Quem recebe instrução e não a transmite terá um espírito formado sem dinamismo nem autocrítica. Nas disciplinas científicas principalmente, esse tipo de instrução cristaliza no dogmatismo o conhecimento que deveria ser um impulso para o caminho inventivo ( $\mathrm{p} .244$ - grifos nossos).

Apesar de se tratarem de autores distintos, é possível dizer que as considerações de Cassam (2016), Freire (1987) e Bachelard (1977) contribuem no entendimento da relação entre vícios intelectuais e obstáculos epistemológicos no contexto da sala de aula. É com base em suas ideias que temos boas razões para afirmar que as raízes psicológicas do autoritarismo em sala de aula, que perturba a construção do conhecimento, tal como o seu avanço, podem se encontrar no orgulho intelectual, na mente fechada e no dogmatismo de um determinado educador enquanto agente epistêmico, isto é, em seus vícios intelectuais.

É possível dizer, portanto, que o dogmatismo, como um vício intelectual, aparece no campo da Educação como um elemento psicológico que fornece condições para a incrustação dos obstáculos epistemológicos. É nesse sentido que, a título de exemplificação, podemos observar que existem no contexto educacional professores e educadores com pensamentos dogmáticos em relação a uma determinada tendência pedagógica e, com isso, a um método específico. Trata-se de um dogmatismo cuja origem se encontra em uma escolha - consciente ou não - a propósito de uma determinada teoria pedagógica.

O problema é que o pensamento dogmático não se coloca diante da crítica. Ele é, portanto, um pensamento fechado, predominante naqueles sujeitos que possuem uma mente fechada. Então, um professor que se orienta dogmaticamente por uma teoria raramente se colocará em disposição para pensar acerca de sua aplicabilidade ou insuficiência perante a realidade educativa, revelando, desse modo, uma má disposição de caráter intelectual no ato educativo.

Essas considerações parecem evidenciar, portanto, a união entre vícios e obstáculos epistêmicos no domínio educacional, na medida em que, de um lado, as ideias que orientam a prática de ensino de um educador são, certamente, aquelas cujos conceitos foram assimilados em seu processo de formação e que se constituíram como sua visão de mundo particular e valorizada acerca do processo educativo e, por outro, trata-se de uma postura dogmática orientada por suas disposições de caráter intelectual. 
Neste ponto, poderíamos pensar a respeito da história das concepções pedagógicas no Brasil. De fato, já foi insistentemente relatado por diversos pesquisadores da ciência da Educação que há, no cenário contemporâneo, a coexistência de diversas concepções (LIBÂNEO, 2013; MIZUKAMI, 1986; SAVIANI, 1984) acerca do processo ensino-aprendizado dentre as quais a tendência pedagógica tradicional ${ }^{8}$ persiste e orienta a prática de ensino dos professores. É ao perceber essa pluralidade de ideias que Libâneo (2020), ressalta a confusão teóricometodológica incutida na mentalidade dos professores: "sua cabeça é escolanovista, a realidade é tradicional; "[...] rejeita o tecnicismo porque sente-se violentado pela ideologia oficial; não aceita a linha crítica porque não quer receber a denominação de agente repressor" (p.2).

A tendência tradicional, face às concepções mais atuais, é geralmente caracterizada por esses autores como uma base cujos conceitos não têm lugar na educação contemporânea, uma vez que ocorre continuamente um movimento de transformação da realidade social. Libâneo (2020) diz que:

Uma boa parte dos professores, provavelmente a maioria, baseia sua prática em prescrições pedagógicas que viraram senso comum, incorporadas quando de sua passagem pela escola ou transmitidas pelos colegas mais velhos; entretanto, essa prática contém pressupostos teóricos implícitos. Por outro lado, há professores interessados num trabalho docente mais consequente, professores capazes de perceber o sentido mais amplo de sua prática e de explicitar suas convicções. Inclusive há aqueles que se apegam à última tendência da moda, sem maiores cuidados em refletir se essa escolha trará, de fato, as respostas que procuram. Deve-se salientar, ainda, que os conteúdos dos cursos de licenciatura, ou não incluem o estudo das correntes pedagógicas, ou giram em torno de teorias de aprendizagem e ensino que quase nunca têm correspondência com as situações concretas de sala de aula, não ajudando os professores a formar um quadro de referência para orientar sua prática (p.1).

As considerações trazidas nessa citação são importantes na medida em que evidenciam a marca dos obstáculos epistemológicos na educação. Libâneo (2020) denuncia a prática pedagógica fundada em conceitos ultrapassados, embora aplicados acriticamente nas situações

\footnotetext{
${ }^{8}$ Uma definição geral é oferecida por Libâneo $(2020$, p.2) que explica que "na tendência tradicional, a pedagogia se caracteriza por acentuar o ensino humanístico, de cultura geral, no qual aluno é educado para atingir, pelo próprio esforço, sua plena realização como pessoa. Os conteúdos, os procedimentos didáticos, a relação professor-aluno não têm nenhuma relação com o cotidiano do aluno e muito menos com as realidades sociais. É a predominância da palavra do professor, das regras impostas, do cultivo exclusivamente intelectual".
} 
concretas da sala de aula, e assim, perturbam a construção de conhecimentos. Para Mizukami (1986), esses conceitos possuem raízes em concepções tradicionais a respeito do ensino, tais como a noção de Homem, de mundo, de aprendizagem, de conhecimento, a visão acerca da relação professor-aluno etc., que ao todo formam um paradigma construído no passado que não mais corresponde à atualidade.

Então, com base nas ideias de Libâneo (2020, 2013), Mizukami (1986) e Bachelard (1977), é possível inferir a seguinte conclusão: a utilização tácita e acrítica de conceitos pedagógicos tradicionais que orientam a prática de ensino do professor revela a existência de obstáculos epistemológicos que atrapalham a construção do conhecimento em sala de aula. As consequências disso são grandes, uma vez que esses obstáculos, como hábitos intelectuais dos professores $^{9}$, contribuem na manutenção das desigualdades sociais no processo de democratização do saber e, portanto, na socialização do educando e na construção de seu desempenho crítico-reflexivo face ao mundo do conhecimento.

Ademais, os professores podem optar deliberadamente por manter práticas tradicionais cuja ineficácia no processo de ensino-aprendizagem já tem sido denunciada porquanto não geram aprendizagens significativas. É nesse ponto que, junto à persistência dessas ideias no campo científico e educativo, ideias que são produtos históricos e sedimentados na cultura pedagógica, observa-se, no professor, uma performance epistêmica viciosa caracterizada pelo orgulho intelectual, com o qual ele acredita ser superior aos seus alunos; pela mente fechada e pelo dogmatismo, com os quais ele pensa que o conjunto de ideias que orienta sua prática de ensino é absolutamente verdadeiro e com isso ele não reflete e não aceita a crítica; pelo excesso de rigor, porquanto em sala de aula ele exige que os alunos assimilem e reproduzam exatamente aquilo que Ihes foi "ensinado", uma fórmula matemática, uma definição de um conceito, um fato histórico etc., não apenas impossibilitando que um aluno chegue às mesmas conclusões por outros caminhos, mas também podando sua autonomia de pensar.

\footnotetext{
${ }^{9}$ Em nenhuma hipótese pretendemos aqui descartar as influências do domínio político na educação e atribuir o sucesso ou fracasso educacional somente ao domínio individual, isto é, à responsabilidade do professor. De fato, nem Libâneo (2020, 2013) nem Mizukami (1986), entre outros autores, dissociam a Educação de seu contexto sociopolítico. Como já acentuamos, as origens dos obstáculos e dos vícios possuem também relações com o contexto social e, uma vez que o social e o político são dois elementos indissociáveis, parece-nos inteiramente possível pensar o último como elemento que contribui na perturbação do conhecimento. Porém, é com base no fator psicológico desses conceitos que fazemos nossa análise neste trabalho.
} 
Então, podemos dizer que obstáculos epistemológicos e vícios intelectuais se apresentam relacionados no contexto educativo e que tal correspondência reforça a análise de Velanes (2020) em seu artigo. Ambas as noções podem ser notadas conjuntamente nas posturas metodológicas adotadas pelos professores em sua prática de ensino cuja causa se encontram em suas condições de caráter intelectual, suas condições psicológicas.

Tal fato parece revelar tanto a existência de vícios, como o dogmatismo e a mente fechada, quanto à adesão valorizada de uma determinada teoria pedagógica ultrapassada, o que revela a existência de obstáculos epistemológicos. Assim, podemos dizer que, no contexto educativo, ambas as noções se encontram. Contudo, concordamos com Velanes (2020) em sua análise entre Bachelard e Cassam, que os vícios favorecem "[...] a uma melhor especificação a respeito dos modos pelos quais os obstáculos podem assumir na busca do conhecimento" (p. 133), uma vez que eles melhor especificam as diversas atitudes de um determinado sujeito epistêmico quando o assunto é a busca do conhecimento.

\section{Referências}

BACHELARD, G. L'activité rationaliste de la physique contemporaine. Paris: PUF, 1965.

BACHELARD, G. L'engagement rationaliste. Paris: PUF, 1972.

BACHELARD, G. La formation de l'esprit scientifique. Paris: J. Vrin, 1977.

BACHELARD, G. Essai sur la connaissance approchée. Paris: J. Vrin, 1986.

BACHELARD, G. Le nouvel esprit scientifique. Paris: PUF, 1999.

BARBOSA, E. Gaston Bachelard: o arauto da pós-modernidade. Salvador: EDUFBA, 1996.

BATTALY, H. Closed-mindedness and dogmatism. Episteme, p.1-22, 2018. DOI:

https://doi.org/10.1017/epi.2018.22. Acesso em: 20 ago. 2020.

BONTEMS, V. Bachelard. Paris: Les Belles Lettres, 2010.

BULCÃO, M. O racionalismo da ciência contemporânea: introdução ao pensamento de Gaston Bachelard. São Paulo: Ideias \& Letras, 2009. 
CASSAM, Q. Vice Epistemolgy. The Monist, n.99, p.159-180, 2016. Acesso em: 5 jul. 2020.

CASSAM, Q. Vices of the Mind. Oxford: Oxford University Press, 2018.

FREIRE, P. Pedagogia do oprimido. Rio de Janeiro: Ed. Paz e Terra, 1987.

LECOURT, D. L'epistémologie historique de Gaston Bachelard. Paris: Vrin, 1978.

LIBÂNEO, J. C. Didática. São Paulo: Cortez, 2013.

LIBÂNEO, J. C. Tendências pedagógicas na prática escolar. Práxis Vivida. p.1-16. Disponível em: https://praxistecnologica.files.wordpress.com/2014/08/tendencias_pedagogicas_libaneo.pdf. Acesso em: 13 ago. 2020.

LÔBO, S. F. Epistemologia bachelardiana e o progresso filosófico das ciências físicas: implicações na química e no ensino de química. In: SILVA FILHO, W. J. (org.). Epistemologia e ensino de ciências. Salvador: Arcádia, 2002. p.245-257.

LÔBO, S. F. O ensino de química e a formação do educador químico, sob o olhar bachelardiano. Ciência \& Educação, v.14, n.1, p.89-100, 2007. DOI: http://dx.doi.org/10.1590/S151673132008000100006. Acesso em: 15 ago. 2020.

LOPES, A. R. C. Livros didáticos: obstáculos verbais e substancialistas ao aprendizado da ciência química. R. Bras. Est. Pedag, Brasília, v.74, n.177, p.309-334, 1993a.

LOPES, A. R. C. Contribuições de Gaston Bachelard ao ensino de ciências. Enseñanza de las Ciencias, Barcelona, v.11, n.3, p.248-274, 1993 b.

MIZUKAMI, M. G. N. Ensino: as abordagens do processo. São Paulo: EPU, 1986.

PARENTE, L. T. S. Bachelard e a química no ensino e na pesquisa. Fortaleza: Edições Universidade Federal do Ceará, 1990.

PENAA, G. B. O; MESQUITA N. A. S. Caracterização de obstáculos epistemológicos na concepção de licenciandos em química que dificultam o desenvolvimento do conhecimento profissional docente. Quim. Nova, v.41, n.8, p.943-952, 2018.

SAVIANI, D. Escola e democracia. São Paulo: Cortez, 1984.

SILVEIRA, F. A; VASCONCELOS, A. K. P; ALMEIDA, S. N; SANTOS NETO, M. B. Investigação dos obstáculos epistemológicos no ensino de química: uma abordagem no tópico modelos atômicos. Ensino de Ciências e Tecnologia em Revista, v.9, n.1, p.31-46, 2019.

VADÉE, M. Bachelard ou le nouvel idéalisme épistémologique. Paris: Ed. Sociales, 1975. 
VELANES, D. OBSTÁCULOS EPISTEMOLÓGICOS E VÍCIOS INTELECTUAIS. Prometheus - Journal of Philosophy, v. 13, n. 35, 12 Feb. 2020.

VELANES, D. Gaston Bachelard e o progresso do saber. Rio de Janeiro: Multifoco, 2018. 